\title{
Synthesis, characterization, bioactivity and biocompatibility of nanostructured materials based on the wollastonite-poly(ethylmethacrylate-co-vinylpyrrolidone) system
}

\author{
L. M. Rodríguez-Lorenzo, ${ }^{1}$ R. García-Carrodeguas, ${ }^{2}$ M. A. Rodríguez, ${ }^{3}$ S. De Aza, ${ }^{3}$ \\ J. Jiménez, ${ }^{4}$ A. López-Bravo, ${ }^{4}$ M. Fernandez, ${ }^{5}$ J. San Román ${ }^{1,4}$ \\ ${ }^{1}$ Instituto de Ciencia y Tecnología de Polímeros (CSIC), C/ Juan de la Cierva 3, 28006-Madrid, Spain \\ ${ }^{2}$ Centro de Biomateriales, Universidad de La Habana, Av. Universidad s/n, e/ G y Ronda, La Habana 10400, Cuba \\ ${ }^{3}$ Instituto de Cerámica y Vidrio (CSIC), Cantoblanco Calle Kelsen 5 28049, Madrid, Spain \\ ${ }^{4}$ Complejo Hospitalario Ávila-Sacyl, Unidad Asociada al CSIC, C/ Jesús del Gran Poder no. 42, 05003 Ávila, Spain \\ ${ }^{5}$ Dept. Farmacología, Facultad de Farmacia, UCM, Pl. Ramón y Cajal s/n 28040-Madrid, Spain
}

Received 11 May 2007; revised 17 July 2007; accepted 8 August 2007

Published online 7 February 2008 in Wiley InterScience (www.interscience.wiley.com). DOI: 10.1002/jbm.a.31867

\begin{abstract}
Composite materials are very promising biomaterials for hard tissue augmentation. The approach assayed in this work involves the manufacturing of a composite made of a bioactive ceramic, natural wollastonite (W) and a nanostructured copolymer of ethylmethacrylate (EMA) and vinylpyrrolidone (VP) to yield a bioresorbable and biocompatible VP-EMA copolymer. A bulk polymerization was induced thermally at $50^{\circ} \mathrm{C}$, using $1 \mathrm{wt} \%$ azobis(isobutyronitrile) (AIBN) as free-radical initiator. Structural characterization, compressive strength, flexural strength (FS), degradation, bioactivity, and biocompatibility were evaluated in specimens with a $60 / 40 \mathrm{VP} / \mathrm{EMA}$ ratio and ceramic content in the range $0-60 \%$. A good integration between phases was achieved. Greater compression and FS, in comparison with the pure copolymer specimens was obtained only when the ceramic load got up to $60 \%$ of the total weight. The soaking in $\mathrm{NaCl}$ solution resulted in the initial swelling of the specimens tested. The maximum swelling was
\end{abstract}

reached after $2-3 \mathrm{~h}$ of immersion and it was significantly greater for lower ceramic loads. This result makes the polymer component the main responsible for the interactions with the media. After soaking in SBF, microdomains segregation can be observed in the polymer component that can be related with a dramatic difference in the reactivity of both monomers in free radical polymerization, whereas the formation of an apatite-like layer on the W surfaces can be observed. Biocompatibility in vitro studies showed the absence of cytotoxicity of all formulations. The cells were able to adhere on the polystyrene negative control and on specimens containing $60 \mathrm{wt} \%$ wollastonite forming a monolayer and showing a normal morphology. However, a low cellular growth was observed. (C) 2008 Wiley Periodicals, Inc. J Biomed Mater Res 88A: 53-64, 2009

Key words: composites; wollastonite; hard tissue replacements; ethylmethacrylate; vinylpyrrolidone

\section{INTRODUCTION}

The design of biomaterials and scaffolds for hard tissue engineering must allow ease of handling in

Correspondence to: L. M. Rodríguez-Lorenzo; e-mail: luis. rodriguez-lorenzo@ictp.csic.es

Contract grant sponsor: Comisión Interministerial de Ciencia y Tecnologia; contract grant numbers: CICYT MAT2003-08331-C02-01, CICYT MAT2004-01654

Contract grant sponsor: NoE Expertissues

Contract grant sponsor: Ramon y Cajal

Contract grant sponsor: National Program for Mobility of Foreign Researchers of the Ministry of Education and Science, Spain; contract grant number: SAB2005-0015

(C) 2008 Wiley Periodicals, Inc. the preparation and implementation of implant materials; furthermore, the implants must have the capacity to be trimmed or sculpted to exactly, fit every surgical site and exhibit a rapid and reproducible degradation or dissolution process in every insertion site. $^{1}$

Mechanical stability and capacity for being osseointegrated are the key features for the success of a bone substitute. Osseointegration requires matching the degradation rate of the substitute to the growing rate of the tissue.

Several approaches have been used to reach this goal, mostly involving the introduction of a bioactive ceramic such as hydroxyapatite ${ }^{2}$ or bioglass. ${ }^{3}$ Several phase composites containing a resorbable polymer and a reinforcing ceramic ${ }^{4}$ is between the most 
promising methods proposed though no ideal bone prostheses have been produced yet. $^{5}$

The approach suggested in this work involves the manufacturing of a composite made of a bioactive ceramic, natural wollastonite, and a nanostructured copolymer with a biostable component, ethylmethacrylate (EMA) and a bioresorbable component, vinylpyrrolidone (VP). These sort of multiphase materials have also shown the ability to create porosity in situ when they are in contact with physiological fluids. ${ }^{6}$

There are two polymorphs of wollastonite; the high temperature form known as pseudowollastonite $(\beta-$ $\left.\mathrm{CaSiO}_{3}, \mathrm{ps}-\mathrm{W}\right)$, and wollastonite-Tc $\left(\alpha-\mathrm{CaSiO}_{3}, \mathrm{~W}-\mathrm{Tc}\right)$, the form stable at temperatures below $1125^{\circ} \mathrm{C}^{7} \mathrm{Ps}-\mathrm{W}$ ceramics react in simulated body fluid (SBF) forming an apatite layer on their surface. ${ }^{8}$ They are not cytotoxic ${ }^{9,10}$ and induce calcification in osteoblast cultures in vitro. ${ }^{11,12} \mathrm{New}$ woven bone is directly deposited on ps-W implants during in vivo test in rat tibiae also. ${ }^{13,14}$ Ps-W ceramics obtained by solid-state reaction of synthetic precursors presented similar chemical, mechanical, and biological properties than ps-W ceramics obtained by sintering powders of natural $\mathrm{W}$ Tc. ${ }^{10} \mathrm{~W}$-Tc ceramics are not available because of the low transition temperature to $\mathrm{ps}-\mathrm{W}$ and the relatively high temperature required for sintering and densification of the precursor powders into a ceramic body. However, synthetic powders of W-Tc exhibit in vitro bioactivity also. ${ }^{15}$ Wollastonite powders and sponges have been employed as fillers in several experimental biomedical composites. Porous ceramic sponges of synthetic ps-W impregnated with a mixture of EMA and VP monomers rendered by thermal polymerization reinforced and in vitro bioactive composites. ${ }^{16,17}$ Biomedical composites of powdered synthetic and natural W-Tc with polymeric matrixes of poly(3hydroxybutirate-co-3-hydroxyvalerate $)^{18-20}$ poly(D,L-lactic acid), ${ }^{21}$ poly(butylene terephthalate), ${ }^{22}$ collagen $^{23}$ and chitosan, ${ }^{24}$ have been reported, which exhibit better mechanical strength and bioactivity with regards to the polymer component alone.

Block copolymers of segments with different solubility properties have been of considerable interest in different fields such as sequestration of pollutants, drug delivery, or gene therapy due to their ability to self-assemble in bulk state. ${ }^{25} \mathrm{VP}$ copolymers have been tested as a vehicle for controlled local application of growth factors. VP acts as a biodegradable support containing the substance to be delivered and the release rate is controlled by the resorption profile of the copolymer composition. ${ }^{26,27} \mathrm{VP}$ has also been tested for the release of the nonsteroidal anti-inflammatory drug 2'4'-difluoro-4-hydroxy$\left(1,1^{\prime}\right.$ biphenyl)-3-carboxylic $\operatorname{acid}^{28}$ and the immunosuppressor cyclosporine A. ${ }^{29}$ The proteic ${ }^{30}$ and blood $^{31}$ interactions of copolymers of VP have also been studied.
Methacrylates have been used in the preparation of acrylic cements ${ }^{32,33}$ used in surgery to fix joint replacements. PEMA bone cements have been investigated as an alternative to PMMA due to their higher ductility, lower toxicity, and exotherm, ${ }^{34}$ water absorptiondesorption characteristics, and interactions with the biological medium studied. ${ }^{35}$ PEMA derivates have been studied for the preparation of intervertebral cages $^{36}$ and as carriers for the recombinant human bone morphogenetic protein $2^{37}$ and fosfosal. ${ }^{38}$

The production of composites based on the in situ polymerization of EMA and VP with several amounts of dispersed W-Tc is presented in this article. The maximum ceramic load that can be achieved is investigated and the influence of the ceramic load on the resorption rate of the specimens and on the features of the apatite layer growth when the specimens are soaked in an acellular SBF is assessed. The influence of the inorganic load in the biocompatibility of the system is also assessed.

The optimization of the resorption rate and the control of the bioactivity in the design of hybrid inorganic-organic composites is the goal pursued.

\section{EXPERIMENTAL SECTION}

\section{Specimen preparation and characterization}

A natural wollastonite (W-Tc) $\left(\right.$ Vansil ${ }^{\mathbb{B}}$ W40, Vanderbilt), with an average particle size of $13.2 \mu \mathrm{m}$ and $1.056 \pm$ $0.001 \mathrm{SiO}_{2} / \mathrm{CaO}$ molar ratio, was selected as the ceramic component. Qualitative X-ray diffraction analysis showed that the major crystalline phase was $\alpha-\mathrm{CaSiO}_{3}$, also called $\mathrm{CaSiO}_{3}$-Tc (JCPDF 43-1460). Minor amounts of prehnite $\left(2 \mathrm{CaO} \cdot \mathrm{Al}_{2} \mathrm{O}_{3} \cdot 3 \mathrm{SiO}_{2} \cdot \mathrm{H}_{2} \mathrm{O}\right.$, JCPDF 29-0290), and diopside (Ca $(\mathrm{Mg}, \mathrm{Al})_{2}(\mathrm{Si}, \mathrm{Al})_{2} \mathrm{O}_{6}$, JCPDF 41-1370) were also detected. ${ }^{10}$ 1-Vinyl-2-pyrrolidone (VP) (Aldrich) and EMA (Acros) were chosen as the organic components for the preparation of the copolymer system.

Prior polymerization, VP, and EMA monomers were distilled at reduced pressure. The monomers were mixed in a VP/EMA 60/40 weight ratio and the ceramic component added in different ceramic/polymer weight ratios: $0 / 100,15 / 85,30 / 70$, and $60 / 40$. The resulting specimens will be named W0, W15, W30, and W60. A bulk polymerization was induced thermally at $50^{\circ} \mathrm{C}$ using 1 wt \% azobis(isobutyronitrile) (AIBN) as free-radical initiator by introducing the desired composition into a $15 \mathrm{~mm}$ diameter cylindrical plastic mold. The molds were filled to a height of $100 \mathrm{~mm}$. Discs of $1 \mathrm{~mm}$ height were sliced with a diamond saw using alcohol as lubricant after removing the cylinders from the mold and discarding $10 \mathrm{~mm}$ length at each end. Plastic molds $(6 \mathrm{~mm})$ were also filled and $12 \times 6$ cylinders manufactured in the same way. $45 \mathrm{~mm}$ length $\times 6 \mathrm{~mm}$ width $\times 4 \mathrm{~m}$ depth teflon molds were also employed.

Specimens with a ceramic/polymer ratio $60 / 40$ and EMA as the solely organic component and films without 
the ceramic component were fabricated in an analogous manner for extra testing.

The specimens were characterized by thermogravimetric analysis (TGA), differential scanning calorimetry (DSC), ${ }^{1} \mathrm{H}$ nuclear magnetic resonance (NMR), attenuated total reflectance Fourier transformed infrared spectroscopy (ATRFTIR), X-ray diffraction (XRD), scanning electron microscopy (SEM) an atomic force microscopy (AFM).

TGA was performed in a Perkin-Elmer TGA 7, three different slices were analyzed to calculate the average value. $10-20 \mathrm{mg}$ of the composites were heated at a $10^{\circ} \mathrm{C}$ / min rate between 50 and $600^{\circ} \mathrm{C}$. DSC experiments were performed in a Perkin-Elmer DSC7. The specimens were heated between 35 and $250^{\circ} \mathrm{C}$ at a rate of $10^{\circ} \mathrm{C}$ in flowing nitrogen gas. Glass transition temperature $\left(T_{\mathrm{g}}\right)$ was estimated from the midpoint of the tangent at the inflection point on the second heating scan. ${ }^{1} \mathrm{H}$ NMR spectra were recorded in a Bruker Avance- 300 working at $300 \mathrm{MHz}$ after extracting the polymeric component in $\mathrm{CDCl}_{3}$. ATRFTIR spectroscopy was performed with a Perkin-Elmer Spectrum one spectrophotometer. Sixteen scans with a 2 $\mathrm{cm}^{-1}$ resolution and $45^{\circ}$ incident angle were recorded between 600 and $4000 \mathrm{~cm}^{-1}$ with a $\mathrm{KBr}$ window yielding an analysis depth of 1-2 $\mu \mathrm{m}$. XRD patterns were recorded in a Siemens D5000 diffractometer in glazing angle mode using $\mathrm{CuK} \alpha$ radiation, $1.5418 \AA$, at an incident angle of 0.5 between $2 \theta 25$ and 35 with a step of $0.02 \AA$ and 10 second per step. Scanning micrographs were taken with an environmental microscope Phillips ESEM XL30 and a Hitachi S4700 field emission microscope field emission microscope. Energy dispersive X-ray analysis (EDAX) and X-ray mapping were applied to identify the elemental distribution. AFM experiments were performed with a Nanoscope IVa controller in a Veeco Multimode. The results were obtained in tapping mode AFM with a phosphorous doped Si cantilever with a oscillation frequency of 217$249 \mathrm{kHz}$. The average roughness for each sample was calculated directly from the AFM images.

\section{Mechanical properties}

Compressive strength (CS) was measured on the $12 \times 6$ $\mathrm{mm}^{2}$ cylinders with an Instrom universal testing machine 3366 with a $5 \mathrm{kN}$ load cell and a crosshead speed of 0.5 $\mathrm{mm} \min ^{-1}$. CS was calculated according to the 5833 ISO Standard with the following formulae

$$
\mathrm{CS}=\frac{F}{A}
$$

where $F$ is the breakload and $A$ the section area of the specimen.

Flexural strength was measured in a three-point configuration in a Microtest EM/50/Fr equipped with a load cell of $0.5 \mathrm{kN}$. The measurements were done following the ASTM D 790-95a standard. The outer span was $25 \mathrm{~mm}$ and the crosshead speed was $1 \mathrm{~mm} \mathrm{~min}^{-1}$. The flexural strength (FS) and flexural modulus of elasticity $\left(E_{\mathrm{f}}\right)$ according to the expressions valid for a three point bending configuration

$$
\begin{aligned}
& \mathrm{FS}=\frac{3 P L}{2 b d^{2}} \\
& E_{\mathrm{f}}=\frac{L^{3} m}{4 b d^{3}}
\end{aligned}
$$

where $P$ is the breakload, $L$ is the support span, $b$ is the specimen width, $d$ is the specimen thickness, and $m$ the slope of the tangent to the initial line portion of the load deflection curve. The results are the average of at least five specimens.

Analysis of variance (ANOVA) was performed by using Statistica 6.0 software (Statsoft, Tulsa, USA). The statistical analysis of wollastonite reinforced specimens was made with respect to wollastonite absent composition used as control, ${ }^{*} p<0.05$.

\section{Degradation and bioactivity}

The kinetics of water absorption and solubility was studied by immersing disks $(n=3)$ of $14 \mathrm{~mm}$ diameter and $1 \mathrm{~mm}$ thickness in $9 \mathrm{~g} / \mathrm{L} \mathrm{NaCl}$ solution $\left(0.1 \mathrm{~mL} / \mathrm{mm}^{2}\right)$ at $36.5^{\circ} \mathrm{C}$ and monitoring the weight of the damped disks after different intervals of immersion time. The percent of water uptake $\left(W_{\mathrm{t}}\right)$ was calculated from the initial dry mass of the disks $\left(m_{0}\right)$ and the mass of the damped disks $\left(m_{\mathrm{t}}\right)$ after certain immersion time by Eq. (4).

$$
W_{\mathrm{t}}=\frac{\left(m_{\mathrm{t}}-m_{0}\right)}{m_{0}} \times 100
$$

Solubility $(S)$ in percent was calculated from $m_{0}$ and the mass of the disks after the longest immersion time, water rinsing and drying to constant weight $\left(m_{\mathrm{f}}\right)$, by using Eq. (5).

$$
S=\frac{\left(m_{\mathrm{f}}-m_{0}\right)}{m_{0}} \times 100
$$

In vitro bioactivity was tested by immersing disks into Kokubo's corrected $\mathrm{SBF}^{39}$ at $36.5^{\circ} \mathrm{C}$ for up to 3 weeks. A volume/area ratio of $0.5 \mathrm{~mL} / \mathrm{mm}^{2}$ was used and the SBF was removed and replaced with a fresh portion at alternate days. Soaked specimens were analyzed by NMR, ATR-FTIR, XRD, SEM, and AFM.

\section{Biocompatibility studies}

Phosphate buffered solution of $\mathrm{pH}=7.4$ (Sigma) was used as received. Thermanox ${ }^{\circledR}$ (TMX) control discs were supplied by Labclinics S. L. Tissue culture media, additives, trypsin and 3-(4,5-dimethylthiazol-2-yl)-2,5 diphenyltetrazolium bromide (MTT), were all supplied by Sigma. The fetal bovine serum was supplied by Gibco and the Alamar Blue reagent by Serotec.

\section{Specimens and cell culture medium}

The negative control was tissue culture plastic, TMX, and the positive control (toxic agent) was an aqueous solu- 
tion of Triton X-100. Discs of $10 \mathrm{~mm}$ diameter and $1 \mathrm{~mm}$ thickness of the cured systems and the controls were used for direct and indirect biocompatibility experiments. At the beginning of the experiment all specimens were sterilized with ethylene oxide. Some specimens were alternatively sterilized with $\beta$-radiation. A dose of $20 \mathrm{kG}$ was supplied to the specimens using an electron accelerator Rhodotron TT2 working at $50 \mathrm{~kW}$ and $10 \mathrm{Mev}$.

The cells used in the primary cell culture were human fibroblasts cultured at $37^{\circ} \mathrm{C}$ in humidified air with $5 \%$ $\mathrm{CO}_{2}$. The culture medium was minimal essential medium Eagle (MEM), modified with HEPES [4-(2-hydroxyethyl)-1piperazine ethane sulfonic acid] (Sigma) and supplemented with $10 \%$ fetal bovine serum, $200 \mathrm{mMl}$-glutamine, 100 units/mL penicillin and $100 \mu \mathrm{g} / \mathrm{mL}$ streptomycin. The culture medium was changed every 2 days with care to cause little disturbance to culture conditions.

\section{Environmental scanning electron microscopy}

The materials were placed in a 24-well plate (in duplicate) and seeded with fibroblasts at a density of $14 \times 10^{4}$ cells $/ \mathrm{mL}$. These were incubated at $37^{\circ} \mathrm{C}$ in humidified air with $5 \% \mathrm{CO}_{2}$. The cells were fixed with $1.5 \%$ glutaraldehyde buffered in $0.1 \mathrm{M}$ phosphate buffer after a 24 -h incubation period. The dried samples were sputter-coated with gold before examination under an environmental scanning electron microscopy (ESEM) apparatus (Philips XL 30) at an accelerating voltage of $15 \mathrm{KeV}$.

\section{MTT assay}

To evaluate the cytotoxicity of the "leachables" obtained from the cured cements, TMX, Triton and discs of formulations were first set up in $5 \mathrm{~mL}$ of MEM and placed on a roller mixer at $37^{\circ} \mathrm{C}$. The medium was removed at 1,2 , and 7 days, and replaced with $5 \mathrm{~mL}$ of fresh medium. All the extracts were obtained under sterile conditions. Human fibroblasts were seeded at a density of $11 \times 10^{4}$ cells $/ \mathrm{mL}$ in complete medium in a sterile 96-well culture plate and incubated to confluence. After $24 \mathrm{~h}$ of incubation the medium was replaced with the corresponding dilution or eluted extract and incubated at $37^{\circ} \mathrm{C}$ in humidified air with $5 \% \mathrm{CO}_{2}$ for $24 \mathrm{~h}$. A solution of MTT was prepared in warm phosphate buffered solution $(0.5 \mathrm{mg} / \mathrm{mL})$ and the plates were incubated at $37^{\circ} \mathrm{C}$ for $4 \mathrm{~h}$. Excess medium and MTT were removed and $100 \mu \mathrm{L}$ dimethylsulphoxide were added to all wells to dissolve the MTT taken up by the cells. This was mixed for $10 \mathrm{~min}$ and the absorbance was measured with a Biotek ELX808IU spectrometer using a test wave length of $570 \mathrm{~nm}$ and a reference wave length of $630 \mathrm{~nm}$. The cell viability was calculated from Eq. (6):

$$
\text { Relative cell viability }(\%)=100 \times \frac{\mathrm{OD}_{\mathrm{S}}-\mathrm{OD}_{\mathrm{B}}}{\mathrm{OD}_{\mathrm{C}}}
$$

where $\mathrm{OD}_{\mathrm{S}}, \mathrm{OD}_{\mathrm{B}}$, and $\mathrm{OD}_{\mathrm{C}}$ are the optical density of formazan production for the sample, blank (MEM without cells) and the corresponding control, respectively.

\section{Alamar Blue assay}

Human fibroblasts were seeded at a density of $14 \times 10^{4}$ cell $/ \mathrm{mL}$ over the testing dry specimens placed in 24 -well culture plate for $24 \mathrm{~h}$. After that, $1 \mathrm{~mL}$ of Alamar Blue dye (10\% Alamar Blue solution in phenol red free DMEM medium) was added to each specimen. After $4 \mathrm{~h}$ of incubation $100 \mu \mathrm{L}(n=4)$ of culture medium for each test sample were transferred to a 96-well plate, and the absorbance was measured at $490 \mathrm{~nm}$ on a Biotek ELX808IU spectrometer. The specimens were washed with phosphate buffered solution twice to remove rest of the reagent, and $1 \mathrm{~mL}$ of culture medium was added to monitor the cells over the materials. This step was done at 4, 7, 14, and 21 days.

Statistical analysis of biocompatibility test

ANOVA was performed by using Statistica 6.0 software (Statsoft, Tulsa, USA). The statistical analysis of MTT, Alamar Blue was made with respect to TMX control, ${ }^{*} p<$ 0.05 .

\section{RESULTS AND DISCUSSION}

\section{Specimen characterization}

The specimens loaded with the ceramic component were characterized first by TGA. A weight loss between 316 and $480^{\circ} \mathrm{C}$ can be observed for each of the compositions analyzed as displayed in Figure 1 (dashed curves), which corresponded to the decomposition and volatilization of the polymer component on heating. From the weight loss ceramic/polymer ratios of the specimens were calculated. Ceramic/ polymer weight ratios obtained for W15, W30, and W60 are: 17/83, 33/67, and 72/28. The deviation

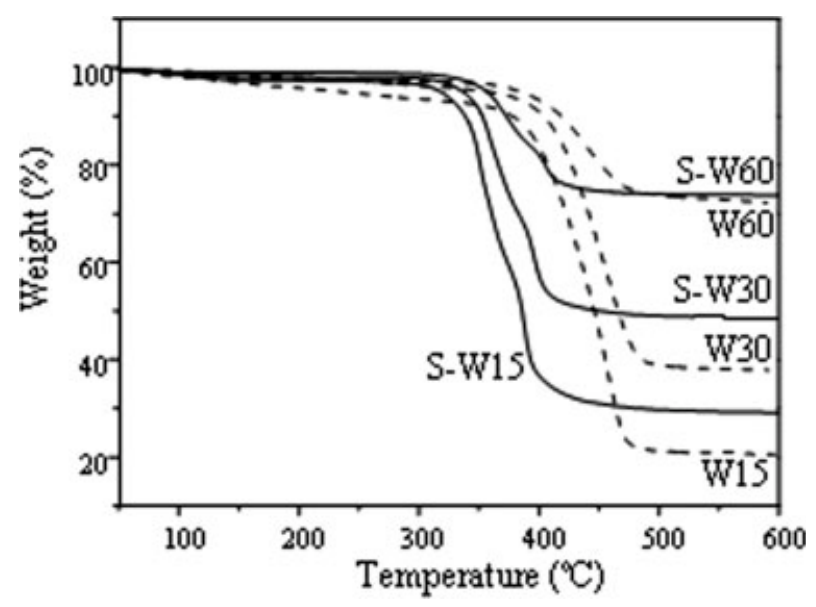

Figure 1. Weight loss on heating of the ceramic containing compositions. W15, W30, and W60 from specimens as prepared, S-W15, S-W30, and S-W60 from specimens soaked in $\mathrm{NaCl}$ solution. 


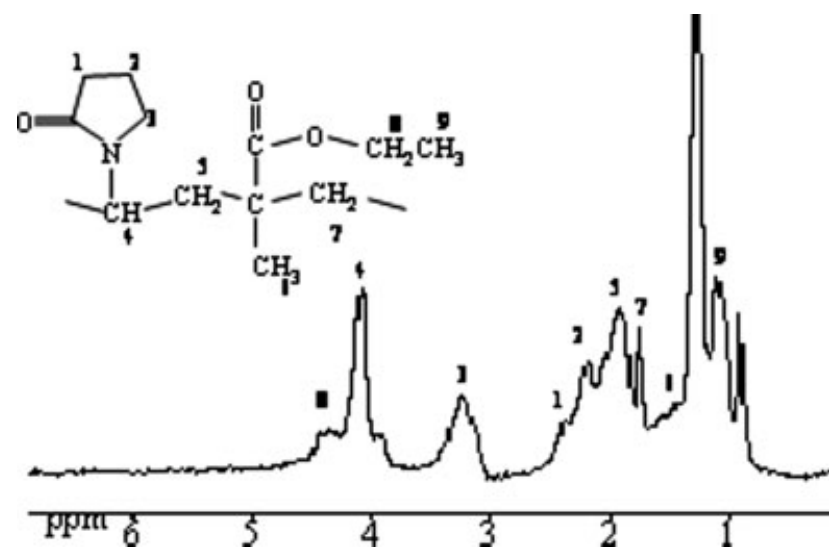

Figure 2. Structure and spectrum of a W0 specimen.

from the ratios utilized for the synthesis was lower than $3 \%$ for those specimens with less than $60 \%$ of $\mathrm{W}-\mathrm{Tc}$ theoretical contents suggesting a reliable preparation procedure. However, remarkable deviation between theoretical and experimental W-Tc content was observed for the specimen W60 probably due to sedimentation of the filler during the thermal polymerization in the cylindrical plastic moulds.

All the weight loss occurred in one single step at a relatively high temperature but the relative stabilization of thermal degradation with respect to pure homopolymers have been reported for several systems including methacrylate units ${ }^{40,41}$ whereas the cleavage of the pyrrolidone ring that could be expected between 280 and $300^{\circ} \mathrm{C}$ has also been observed at greater temperatures as a consequence of the volatilization of the pyrrolidone residue that proceeds from polyenic sequences formed at those temperatures. ${ }^{40,41}$

The DSC analysis of the copolymer specimens without the ceramic component showed a unique $T_{\mathrm{g}}$ at about $60^{\circ} \mathrm{C}$ that is very close to the theoretical value for PEMA. ${ }^{42}$ When the ceramic component is added the $T_{\mathrm{g}}$ value shifts to $88^{\circ} \mathrm{C}$, suggesting that an interaction between the ceramic and the polymeric components does happen. No significant differences could be appreciated between specimens with different ceramic load.
Polymerization was confirmed by ${ }^{1} \mathrm{H}$ NMR spectroscopy. Figure 2 displays the spectrum of the copolymer for a W0 specimen. The spectrum corresponds to a random EMA/VP copolymer with an average weight composition 60/40 which was determined from the comparison of the resonance signals of the oxyethylene groups of EMA units (4.1 ppm) and those assigned to the pyrrolidone ring (3.4 ppm). Results for each of the compositions are shown in Table I.

The SEM images and $\mathrm{Ca}$ and $\mathrm{Si}$ mappings displayed in Figure 3 show that the specimens are made of acicular W-Tc particles distributed within a homogeneous polymeric matrix. No cracks between the organic and the inorganic phase can be observed indicating that a good integration between phases was achieved.

\section{Mechanical properties}

The CS results of the composite specimens are shown in Table I. Compression strength is greater for W60 than for the copolymer specimens W0. W30 and W15 compression strength results are not significantly different from W0. The elasticity modulus in compression mode is also displayed in Table I. A $47 \%$ and $20 \%$ increase for the W60 and W30 specimens in comparison to the non-reinforced specimens (W0) was obtained whereas the W15 composition does not show a significant increase in elastic modulus compared with the non-reinforced specimen.

Flexural strength results are also collected in Table I. Each of the ceramic reinforced compositions shows a greater FS than the non-reinforced copolymer specimens. Again, the maximum FS was achieved for the composition with a $60 \%$ of ceramic load. W15 and W30 compositions showed no significant difference between them, but their values are significantly lower than those of W60. The elasticity modulus calculations in bending yield greater values for greater ceramic loadings.

Bending fracture surfaces are displayed in Figure 4 revealing the influence of filler particles on the deformation of the copolymer. W0 fracture surface is

TABLE I

Composition and Mechanical Properties of the Specimens

\begin{tabular}{|c|c|c|c|c|c|c|c|c|c|c|}
\hline & \multicolumn{3}{|c|}{ As Prepared } & \multicolumn{3}{|c|}{ Soaked in $\mathrm{NaCl}(0.9 \%)$} & \multicolumn{4}{|c|}{ As Prepared } \\
\hline & $\begin{array}{c}W \\
(w t \%)\end{array}$ & $\begin{array}{c}\mathrm{VP} \\
(w \mathrm{t} \%)\end{array}$ & $\begin{array}{c}\text { EMA } \\
(w t \%)\end{array}$ & $\begin{array}{c}W \\
(w t \%)\end{array}$ & $\begin{array}{c}\mathrm{VP} \\
(w \mathrm{t} \%)\end{array}$ & $\begin{array}{l}\text { EMA } \\
\text { (wt \%) }\end{array}$ & $\begin{array}{c}\mathrm{CS} \\
(\mathrm{MPa})\end{array}$ & $\begin{array}{c}E_{\mathrm{c}} \\
(\mathrm{GPa})\end{array}$ & $\begin{array}{c}\mathrm{FS} \\
(\mathrm{MPa})\end{array}$ & $\begin{array}{c}E_{\mathrm{f}} \\
(\mathrm{GPa})\end{array}$ \\
\hline W0 & 0 & 60 & 40 & 0 & 60 & 40 & $42(8)$ & $2.8(2)$ & $20(9)$ & $0.184(1)$ \\
\hline W15 & 17 & 51 & 32 & 28 & 44 & 28 & $39(14)$ & $2.6(5)$ & $50(10)$ & $1.4(3)$ \\
\hline W30 & 33 & 42 & 25 & 48 & 30 & 22 & $40(15)$ & $3.4(1)$ & $59(8)$ & $3.0(6)$ \\
\hline W60 & 72 & 17 & 11 & 72 & 17 & 11 & $59(9)$ & $4.1(1)$ & 75 (9) & 4.19 (5) \\
\hline
\end{tabular}



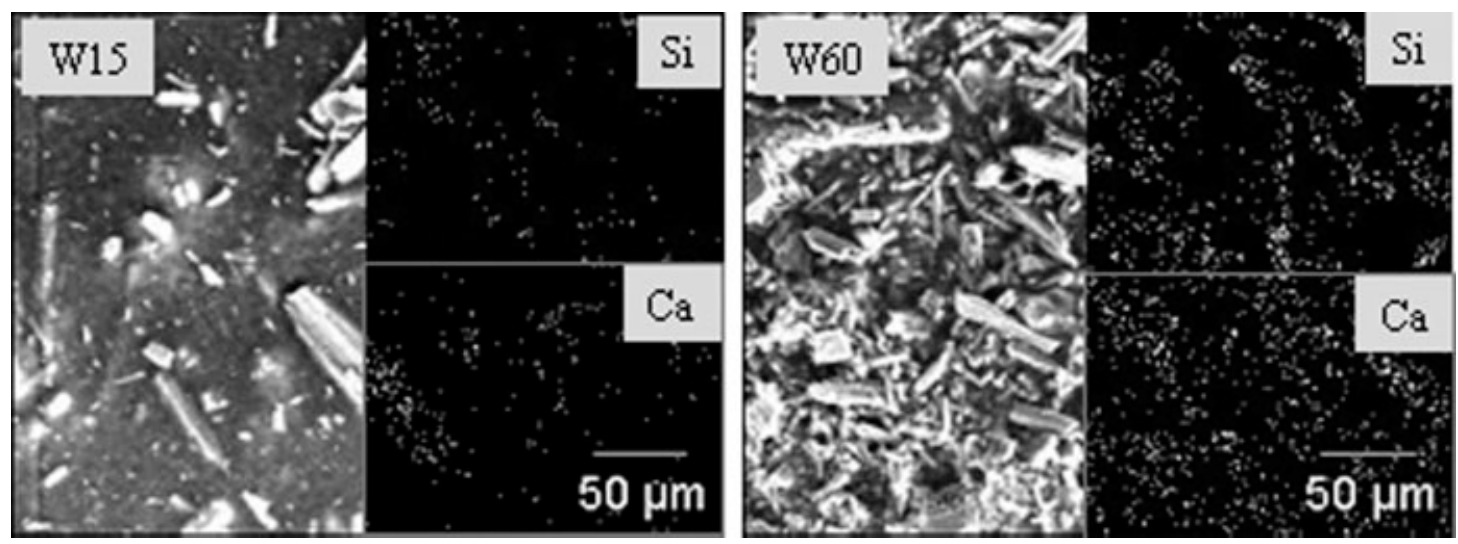

Figure 3. SEM picture and Si and Ca mapping of W15 and W60 specimens.

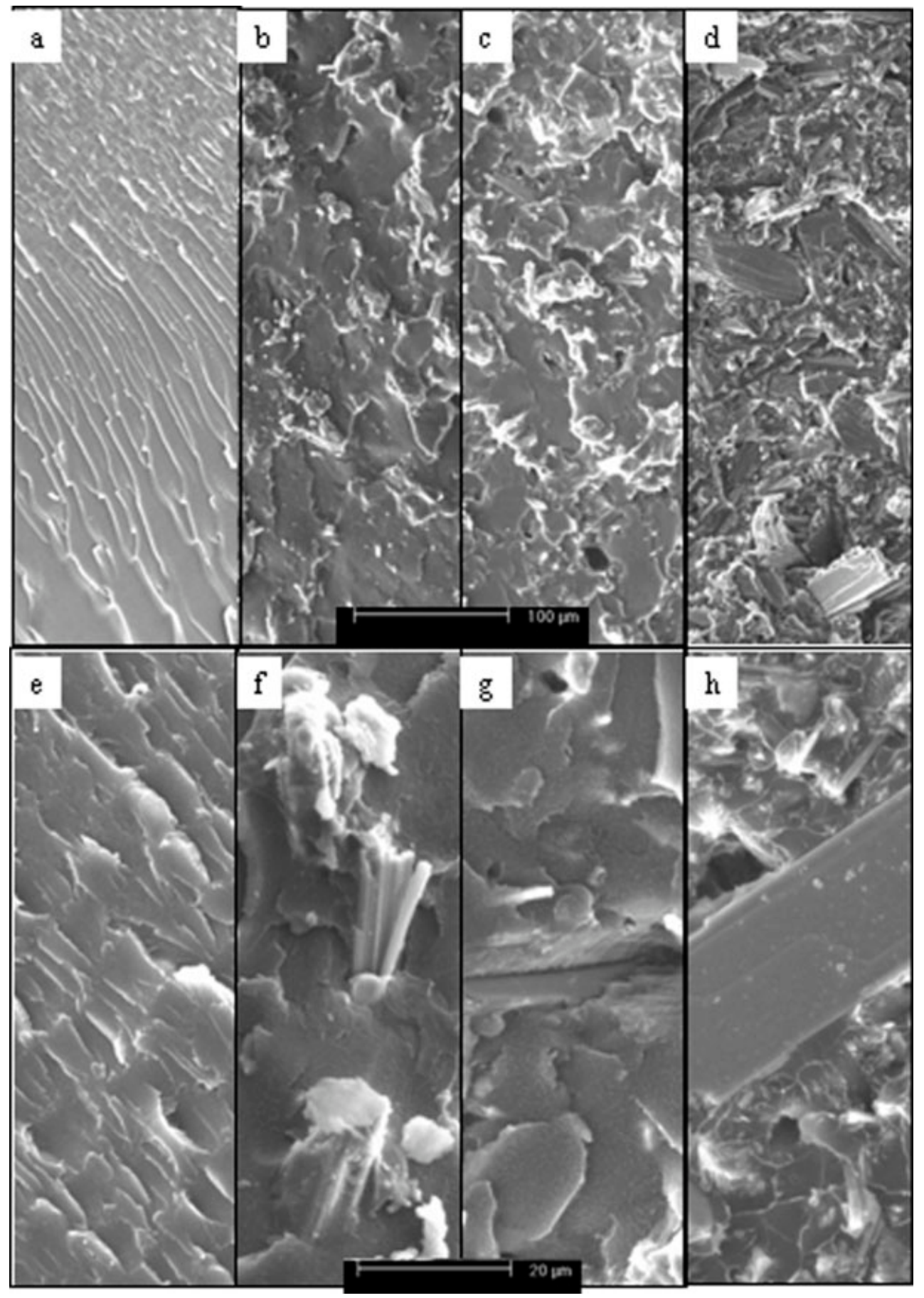

Figure 4. Fracture surface and magnification of W0 (a,e); W15 (b,f); W30 (c,g); W60 (d,h). 


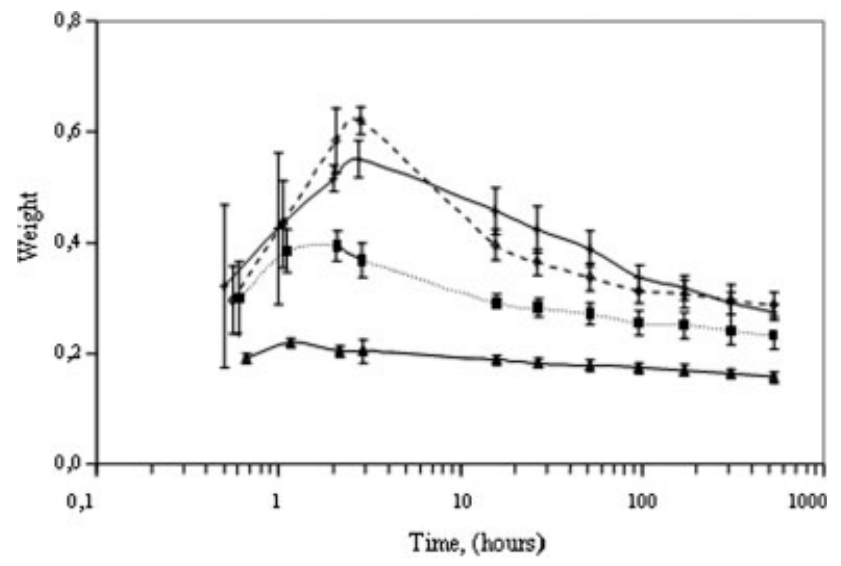

Figure 5. Kinetics of water uptake for the noncharged copolymer and the experimental composites. ——: W0; - - : W15; ... W: W30; ־-: W60.

shown in Figure 4(a) and a magnification is displayed in Figure 4(e). The polymer is highly deformed with elongated domains that indicate a ductile fracture. W15 fracture surfaces show ceramic particles and agglomerates with copolymers domains surrounding them with no apparent voids between phases, domains are less deformed indicating a lower ductile character of the fracture, Figure $4(\mathrm{~b}, \mathrm{f})$. Broken ceramic particles and less deformed polymer matrix were observed for greater ceramics loads indicating fragile fractures, Figure $4(\mathrm{c}-\mathrm{d}, \mathrm{g}-\mathrm{h})$.

Some studies in particulate filled resins have shown that a low degree of adhesion between the particles and the matrix produces a decrease in yield stress. ${ }^{43}$ Other studies in particulate filled PMMA cements have shown that the poor adhesion between the filler and the matrix can be compensated by increasing the filler content resulting in constant values of the yield stress. ${ }^{44}$ The studied compositions seem to reproduce this compensation mechanism where only the effects of the greater amount of filler content totally overcome the effect of the lack of adhesion resulting in a greater compression strength. However, in bending mode, the ceramic particles seems to interact with the polymer repressing the ductile behavior of the polymer as it can be observed in the fracture surface and increasing the value of the fracture stress. Maximum bending stress was reached at values over $50 \%$ of filler content in good agreement with results obtained in polyethylene composites. ${ }^{45}$ There are several mechanisms that can explain the improvement in the fracture stress in bending of particulate reinforced polymers, one of them is known as crack pinning. ${ }^{46}$ If a crack begins to propagate within a material, the crack front bows outward between two rigid particles before breaking free. The crack front elongates as it bows out, absorbing fracture energy. Separation of the filler from the matrix also absorbs energy. As the advancing crack intersects with particles a further opening of the tip requires extra energy to separate the filler matrix interfaces. Poorly bonded fillers do not contribute effectively to toughening through this mechanism. Thus, the improvement in the bending stress of the reinforced specimens together with the shift from ductile to fragile behavior observed in the scanning micrographs seems to indicate some sort of interaction in the selected system.

Elastic modules in compression were all greater than the elastic modulus of PMMA cements determined to be $1.6 \mathrm{GPa}^{47}$ and closer to the compressive modulus of compact bone for femur reported to be up to $17 \mathrm{GPa}^{48}$ and they are greater than the values obtained for several calcium phosphate cements, reported to range between 0 and $51 \mathrm{MPa}^{49}$ Thus, these compositions have the mechanical behavior appropriate to consider them as good candidates for bone or dental replacement. However, wollastonite
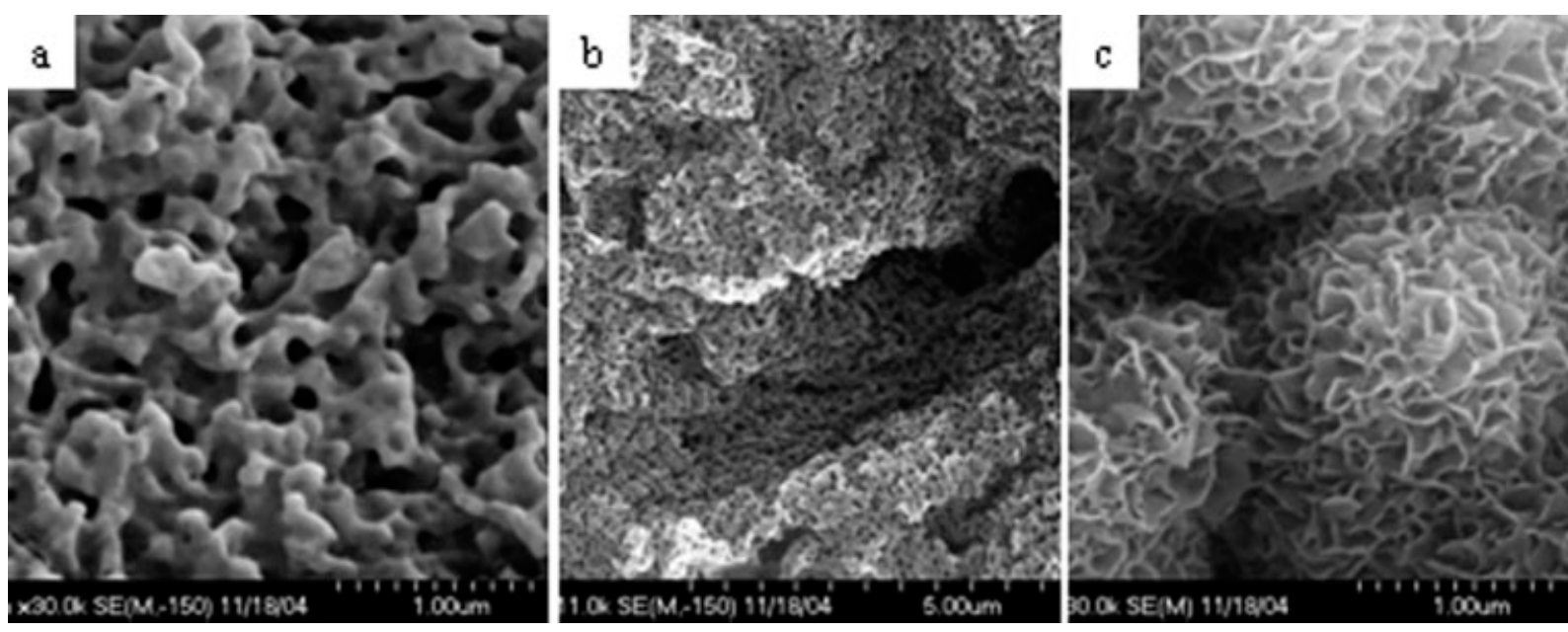

Figure 6. SEM pictures of specimens soaked in SBF for 3 weeks, (a) W0; (b) W15; (c) W30, and (d) W60. 


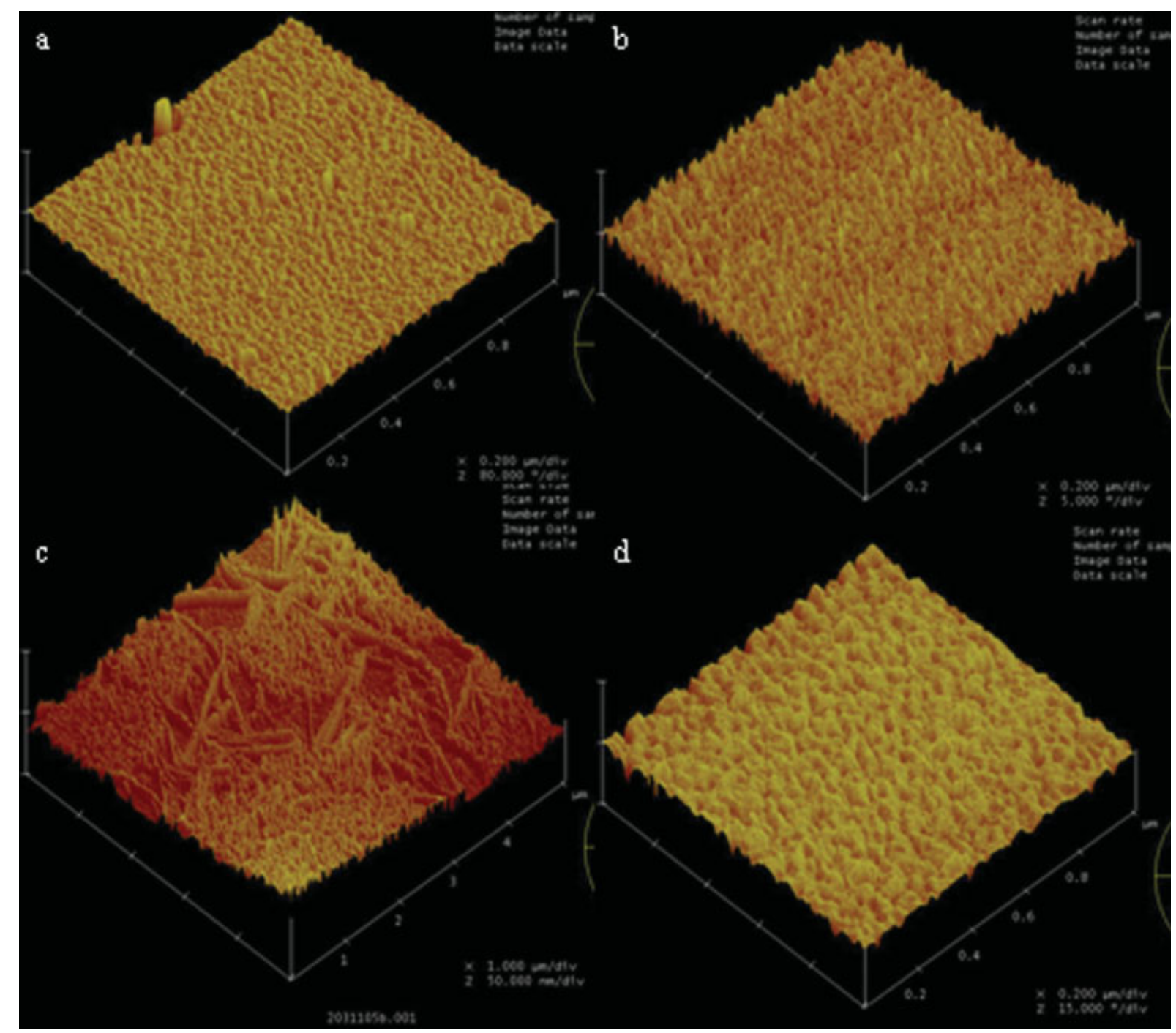

Figure 7. AFM images of (a) VP/EMA 60/40; (b) EMA 100\%; (c) VP/EMA 60/40 soaked CaCl 48 h; (d) EMA 100\% soaked $\mathrm{CaCl}_{2} 48 \mathrm{~h}$. [Color figure can be viewed in the online issue, which is available at www.interscience.wiley.com.]

seems to be little studied as filler material in dental replacements. ${ }^{50}$

\section{Degradative behavior/bioactivity}

The soaking in $\mathrm{NaCl}$ solution resulted in the initial swelling of the specimens tested. The maximum swelling was reached after $2-3 \mathrm{~h}$ of immersion and it was significantly greater for W0 and W15 than for W30. The maximum swelling of W30 was also greater than that of W60. These results make the polymer component the main responsible for the interactions with the media, which are the driving forces of the water uptake. At the macroscopic scale, the porosity of the polymer matrix should be the main factor for water absorption through capillarity phenomena, whereas in microscopic terms, the highly hydrophilic VP rich moieties existing in the copolymer chains must provide them with waterbinding capacity trough hydrogen and dipole-dipole Van der Waals bonding. The matrix-filler interface seems to have none effect on the water absorption of the composites.

The kinetic curves of Figure 5 also revealed that, after reaching the corresponding values of maximum swelling, the copolymer and the experimental composites started to lose weight due to dissolution. The values of $S$ found were $35.9 \pm 1.6,33.2 \pm 1.8,24.9 \pm$ 1.5 , and $13.9 \pm 2.0 \%$ for W0, W15, W30, and W60, respectively, and diminished as the $\mathrm{W}$-Tc content increased suggesting that the EMA/VP copolymer is more soluble than the W-Tc filler. After finishing the soaking in $\mathrm{NaCl}$ solution the specimens were submitted to NMR and TGA to determine possible changes in copolymer composition and ceramic/ polymer weight ratio due to incongruent dissolution of the composite. 


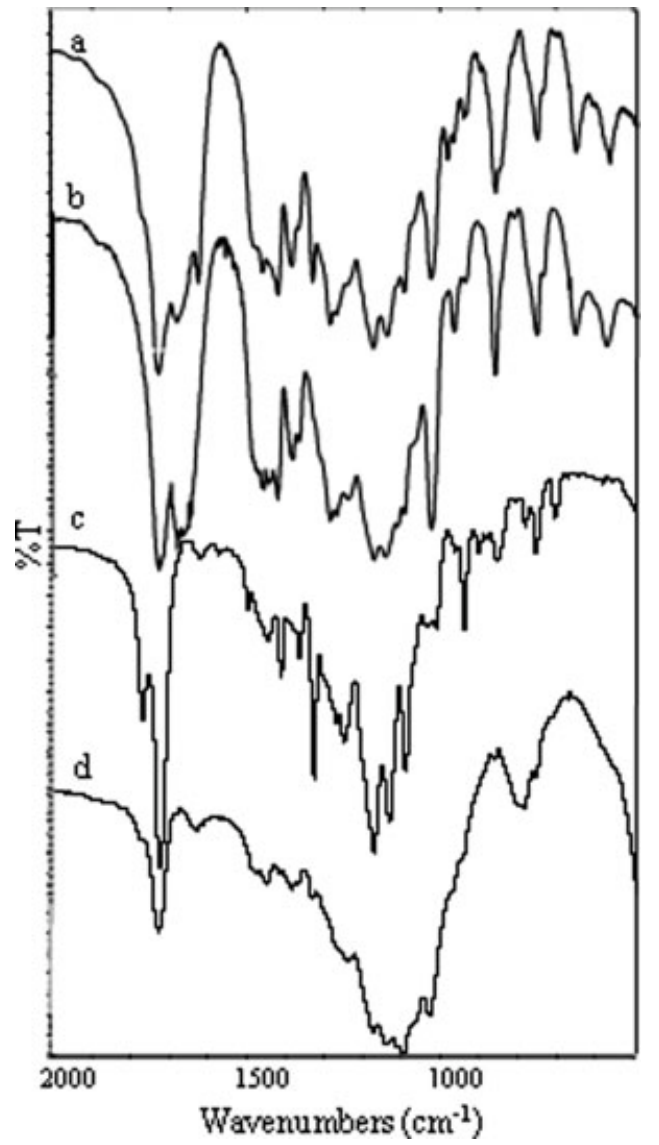

Figure 8. FTIR spectra of (a) VP/EMA 60/40; (b) VP/ EMA 60/40 soaked $\mathrm{CaCl}_{2} 48$ h (c) EMA 100\%; (d) EMA $100 \%$ soaked $\mathrm{CaCl}_{2} 48 \mathrm{~h}$.

The results are shown in Table I. The ceramic/ polymer weight ratio grew after the immersion in $\mathrm{NaCl}$ as expected, due to the partial dissolution of the copolymer component of the composites whereas the sparingly soluble W-Tc was not affected. However, the VP/EMA ratio in soaked samples remained almost invariable $(\cong 1.5 \pm 0.1)$ suggesting either congruent dissolution of the copolymer or more likely as it will be discussed later a dissolution of the VP domains that remain absorbed on the surface of the $\mathrm{W}$ component. ${ }^{51}$ This result indicates a homogeneous microstructure of the copolymer characterized by uniform distribution of both monomers in the copolymer chains.

In contrast to as prepared composites, after soaking in saline for 22 days the TGA curves of the specimens W15, W30, and W60 presented multistep weight reductions (Fig. 1, solid curves). The first step in weight loss between 60 and $160^{\circ} \mathrm{C}$, ranging between 1 and 3\% and directly related to the polymer content, could be assigned to the removal of absorbed water. The second event started at $280^{\circ} \mathrm{C}$ and extended to $375-400^{\circ} \mathrm{C}$. The weight loss related to this event were 38,28 , and $15 \%$ for W15, W30, and W60, respectively, and is probably caused by the releasing of pyrrolidone side groups ${ }^{40,41}$ and the depolymerization of the saturated products of the disproportion of poly(ethyl methacrylate) sequences in the copolymer chains. ${ }^{52,53}$ From $375-390^{\circ} \mathrm{C}$ to $460^{\circ} \mathrm{C}$ a third step could be distinguished due to the decomposition of the polyenic sequences remaining from the poly(vinylpyrrolidone) moieties, into lowmolecular weight hydrocarbon compounds, ${ }^{40,41}$ as well as the continuing depolymerization of the products of disproportion of poly(ethyl methacrylate). ${ }^{52,53}$ The corresponding weight loss were 31, 23, and $12 \%$ for $\mathrm{W} 15, \mathrm{~W} 30$, and $\mathrm{W} 60$, respectively. The better resolution of the thermal effects in soaked specimens can be explained by the increase of porosity originated by partial dissolution of the polymeric matrix, which contributes to the faster removal of the volatile decomposition products from the composites bulk.

After soaking the specimens in SBF for a week, two different phenomena were observed (a) in the polymeric matrix, a porous nanostructure was formed [Fig. 6(a,b)] indicating microdomains of different solubility. Those zones that appeared to be dissolved should be related to the more resorbable VP rich microdomains, whereas those zones that seems to be unaffected by the immersion should correspond to the more stable EMA rich domains. This microdomain segregation can be related with a dramatic difference in the reactivity of both monomers in free radical polymerization; (b) on the $\mathrm{W}$ surfaces, the formation of an apatite-like layer was observed by SEM [Fig. 6(c)], which after studied by ATR-FTIR and low angle XRD could be attributed to a carbohydroxyapatite (CHA). The thickness of the layer is greater for greater percentages of $\mathrm{W}$. At $60 \mathrm{wt} \%$ of $\mathrm{W}$ all the composite was covered with a thick layer of $\mathrm{CHA}$.

The growing rate and thickness of the apatite layer seems to be lower than the layer observed in other systems. ${ }^{54}$ An inhibition of the growing of the apatite layer is thought to be related to an interaction between the VP component and the Ca of the SBF. Films containing a $60 / 40 \%$ VP/EMA and $100 \%$ EMA were prepared in an analogous way than the former specimens and soaked in $\mathrm{CaCl}_{2}$ solution to test this hypothesis. AFM analysis on the surfaces of the films permitted to appreciate the different behavior of the films whether VP was present or not. Figure $7(a, b)$ shows the surface of the VP/EMA $60 / 40$ and EMA100 films. The presence of VP leads the mean roughness measured from the $1 \mu \mathrm{m}$ scan of the films from Ra $0.294 \mathrm{~nm}$ for EMA100 to Ra 0.665 $\mathrm{nm}$ for VP/EMA60/40. After soaking, EMA 100 film surface seems similar than before but with a roughness of Ra $0.665 \mathrm{~nm}$. The surface of the VP/EMA film was not homogeneous anymore showing the appearance of some structures that lead the rough- 


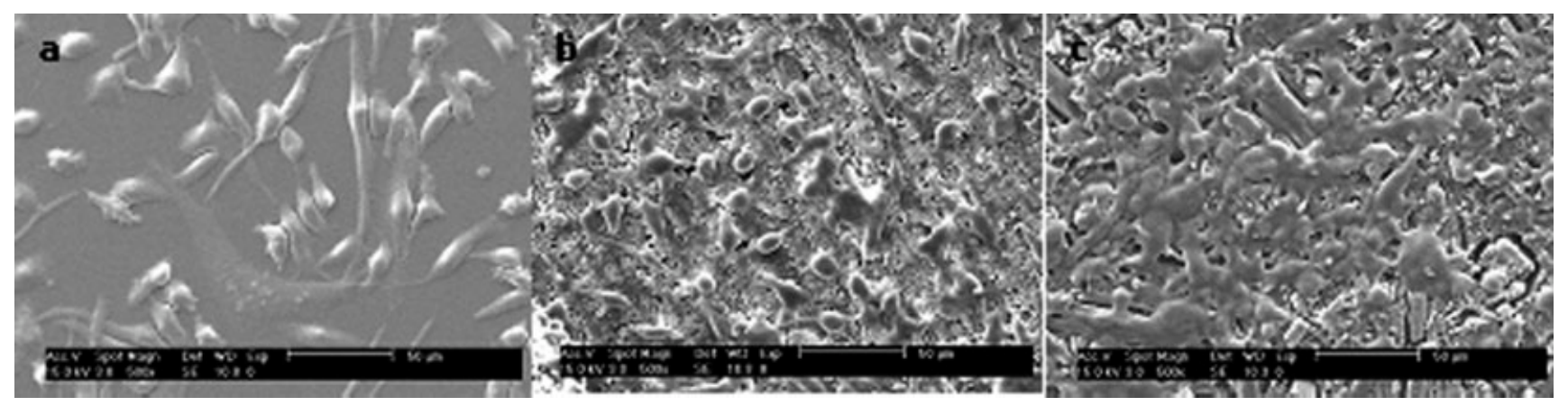

Figure 9. SEM images $(\times 500)$ of human fibroblasts colonization over the control (TMX) (a), the W60 material sterilized with ethylene oxide (b) and with $\beta$-radiation (c) at 1 day.

ness to Ra $4.911 \mathrm{~nm}$ suggesting a stronger interaction with the solution either with the water due to the hydroscopic nature of the VP or with the calcium. The IR spectrum of the $60 / 40$ film soaked for $48 \mathrm{~h}$ [Fig. 8(b)] showed the disappearance of the band at $1629 \mathrm{~cm}^{-1}$ assigned to the carbonyl group from the VP component whereas no significant differences may be observed in the spectrum of the soaked 100\% EMA film, [Fig. 8(d)]. These results suggest the interaction of the calcium with the VP component in a way that can interfere with the initial stages of formation of the layer of carbonateapatite in bioactive materials.

\section{Biocompatibility studies}

Results of direct contact of cells with materials after 1 day of seeding are shown in Figure 9. In all micrographs flattened fibroblasts were observed over the surfaces. Fibroblasts showed no evidences of morphological changes after $24 \mathrm{~h}$ of incubation in the presence of W60 material when compared with control independently of its form of sterilization: ethylene oxide or $\beta$ radiation.

MTT assay was used to measure cell metabolic function. This test is dependent on the intact activity

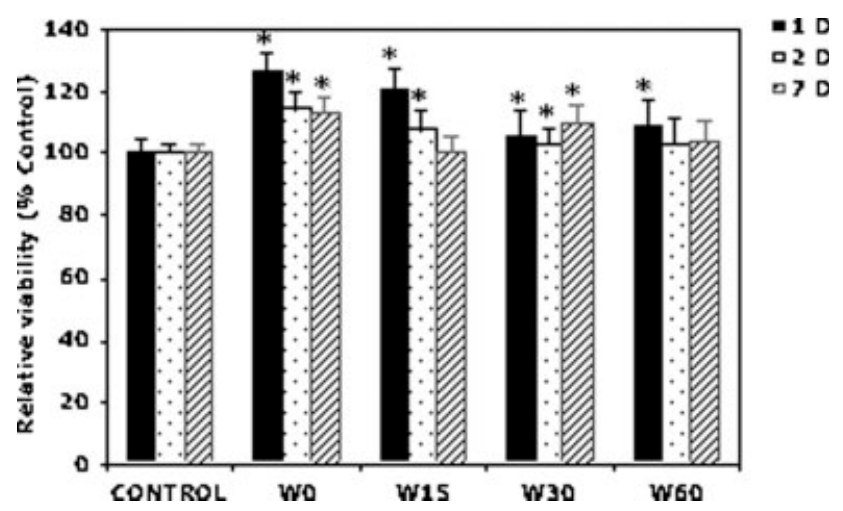

Figure 10. MTT cytotoxicity results for the control and the "leachables" of test materials. Results are the mean \pm standard deviation; $n=8 ;\left({ }^{*} p<0.05\right.$ respect to control). of a mitochondrial enzyme, succinate dehydrogenase, which may be impaired after exposure of cells to toxic species. ${ }^{55}$ MTT results showed the absence of mitochondrial damage in any of the experimental formulations. All the compositions present a biocompatibility at least of the level or even superior than the TMX control as can be seen in Figure 10.

Cell growth and proliferation were assessed by Alamar Blue assay. $A B$ is a redox indicator that changes color with the chemical reduction of the culture medium occurring as the result of cells growth and proliferation. This reagent can be withdrawn and replaced with fresh medium, for monitoring cell proliferation. It is soluble, stable in culture media and nontoxic to cells. ${ }^{56}$

Results from this assay are shown in Figure 11. The number of cells adhered to materials were less than to the control, but when increasing the amount of $\mathrm{W}$ in each formulation, cells growth and proliferate better, although without reaching the values for the control. This behavior can be explained based on the high roughness of the materials. It is known that the cell behavior depends on surface roughness and surface free energy. ${ }^{57}$

In vitro biocompatibility studies showed the absence of cytotoxicity of all formulations. The cells

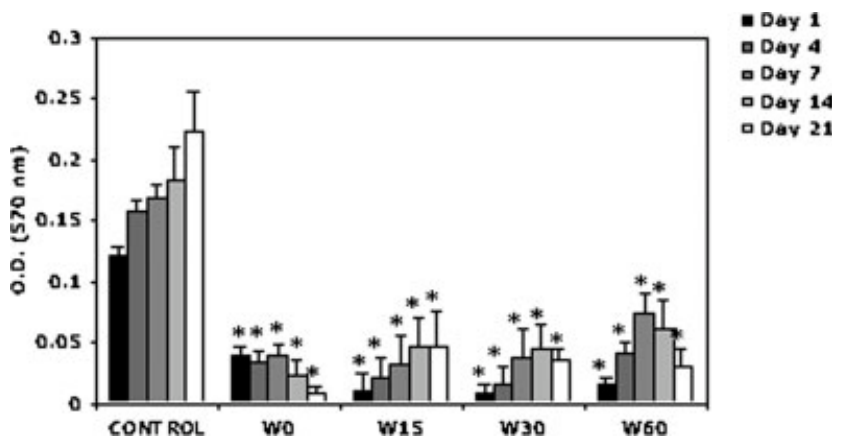

Figure 11. Direct Alamar Blue results for control TMX and formulations over a 21-day period. Results are the mean \pm standard deviation; $n=8 ;\left({ }^{*} p<0.05\right.$ respect to control). 
were able to adhere on the TMX control and W60 formulation forming a monolayer and showing a normal morphology. However, there was less cellular growth with respect to control (TMX) as it can be observed in the Alamar Blue assay. This phenomenon may be due to the surface properties. Surface roughness of our specimens is very high and it is difficult for cells to adhere and growth. Glass ceramic formulations with polished and smooth surfaces improve the cell adhesion and cell proliferation. ${ }^{58}$

\section{CONCLUSIONS}

The results suggest that wollastonite-poly(VP-coEMA) composites provide with new bioactive materials that are able to develop nanoporous structures in physiological conditions. Mechanical properties of the system make it suitable for bone substitution. The highest ceramic load is the most promising composition due to the combination of good mechanical behavior, bioactivity, and biocompatibility with appropriate surfaces for cell proliferation.

\section{References}

1. Caplan AI. New logic for tissue engineering: Multifunctional and biosmart delivery vehicles. In: Davies JE, editor. Bone Engineering. Toronto: Em Squared; 1998. p 441-446.

2. Bonfield W. Hydroxyapatite reinforced polyethylene as an analogous material for bone replacement Ann NY Acad Sci 1988;523:173-177.

3. Wang M, Hench L Bonfield W. Bioglass/high density polyethylene composite for soft tissue applications: Preparation and evaluation. J Biomed Mater Res 1998;42:577-586.

4. Rodríguez-Lorenzo LM, Salinas AJ, Vallet-Regí M, San Román J. Composite biomaterials based on ceramic-polymers I: Reinforced systems based on Al2O3/PMMA/PLLA. J Biomed Mater Res 1996;30:515-522.

5. McManus AJ, Doremus RH, Siegel RW Bizios R. Evaluation of cytocompatibility and bending modulus of nanoceramic/ polymer composites. J Biomed Mater Res A 2005;72:98-106.

6. De Aza PN, Guitian F, De Aza S. Bioeutectic: A new ceramic material for human bone replacement. Biomaterials 1997;18: 1285-1291.

7. Phillips B, Muan A. Phase equilibriums in the system calcium oxide-iron oxide-silica in air. J Am Ceram Soc 1959;42:413423.

8. De Aza PN, Guitian F, Merlos A, Lora-Tamayo E, De Aza S. Bioceramics-simulated body fluid interfaces: $\mathrm{pH}$ and its influence on hydroxyapatite formation. J Mater Sci: Mater Med 1996;7:399-402.

9. Dufrane D, Delloye C, Mckay IJ, de Aza PN, de Aza S, Schneider YJ, Anseau M. Indirect cytotoxicity evaluation of pseudowollastonite. J Mater Sci Mater Med 2003;14:33-38.

10. García Carrodeguas R, De Aza A, De Aza PN, Baudín C, Jimenez J, López-Bravo A, Pena P, De Aza S. Assessment of natural and synthetic wollastonite as source for bioceramics preparation. J Biomed Mater Res A. Forthcoming.

11. Sarmento C, Luklinska ZB, Brown L, Anseau M, de Aza PN, de Aza S, Hughes FJ, Mckay IJ. In vitro behaviour of osteo- blastic cells cultured in the presence of pseudowollastonite ceramic. J Biomed Mater Res 2004;69A:351-358.

12. Brown L, Lublinska ZB, De Aza PN, De Aza S, Anseau M, Hughes FJ, McKay IJ. Proceedings of the Seventh World Biomaterials Congress, Sydney, Australia, 2004.

13. De Aza PN, Lublinska ZB, Martinez A, Anseau MR, Guitián F De Aza S. Morphological and structural study of pseudowollastonite implants in bone. J Microsc 2000;197:60-67.

14. de Aza PN, Luklinska ZB, Anseau M, Guitian F de Aza S. Transmission electron microscopy of the interface between bone and pseudowollastonite implant. J Microsc 2001;201:3343.

15. Wan X, Chang C, Mao D, Jiang L, Li M. Preparation and in vitro bioactivities of calcium silicate nanophase materials. Mater Sci Eng C: Biomater 2005;S25:455-461.

16. Rodríguez-Lorenzo LM, García-Carrodeguas R, Rodríguez MA, De Aza S, Jiménez J, López-Bravo A, Fernández M, San Román J. Wollastonite-poly(ethylmethacryltae-co-vinylpyrrolidone) nanostructured materials: Mechanical properties and biocompatibility. Key Eng Mater 2006;309-311:1149-1152.

17. Rodríguez-Lorenzo LM, García-Carrodeguas R, Rodríguez MA, De Aza S, Jiménez J, López-Bravo A, Fernández M, San Román J. Development of wollastonite poly(ethylmethacrylate-co-vinylpyrrolidone) based materials fro multifunctional devices. J Biomed Mater Res A 2007;80A. DOI 10.1002/jbm.a. 30956.

18. Li H, Chang J. Fabrication and characterization of bioactive/ PHBV composite scaffolds. Biomaterials 2004;25:5473-5480.

19. Li H, Chang J. In vitro degradation of porous degradable and bioactive PHBV/wollastonite composite scaffolds. Polym Degrad Stabil 2005;87:301-307.

20. Li H, Chang J. Preparation, characterization and in vitro release of gentamicin from $\mathrm{PHBV} /$ wollastonite composite microspheres J Control Release A 2005;107:463-473.

21. Li H, Chang J. Preparation and characterization of bioactive and biodegradable wollastonite/poly(D,L-lactic acid) composite scaffolds. J Mater Sci: Mater Med 2004;15:1089-1095.

22. Risbud M, Saheb DN, Jog J, Bhonde R. Preparation, characterization and in vitro biocompatibility evaluation of poly(butylene terephtalate)/wollastonite composites. Biomaterials 2001;22:1591-1597.

23. Li X, Chang J. Preparation and characterization of bioactive collagen/wollastonite composite scaffolds. J Mater Sci: Mater Med 2005;16:361-365.

24. Zhao L, Chang J. Preparation and characterization of macroporous chitosan/wollastonite composite scaffolds. J Mater Sci: Mater Med 2004;15:625-629.

25. Ma Q, Wooley KL. The preparation of $t$-butyl acrylate, methylacrylate, and styrene block copolymers by atom transfer radical polymerization: Precursors to amphiphilic and hydrophilic block copolymers and conversion to complex nanostructured materials J Polym Sci Part A: Polym Chem 2000; 38:4805-4820.

26. Cifuentes A, Diez-Masa JC, Montenegro C, Rebuelta M, Gallardo A, Elvira C, San Roman J. Recombinant growth hormone delivery systems based on vinylpyrrolidone-hydroxyethyl methacrylate copolymer matrices: Monitoring optimization by capillary zone electrophoresis J Biomater Sci: Polym Ed 2000;11:993-1005.

27. Gimeno MJ, Garcia-Esteo F, Garcia-Honduvilla N, San Roman J, Bellon JM, Bujan J. A novel controlled drug-delivery system for growth hormone applied to healing skin wounds in diabetic rats. J Biomater Sci: Polym Ed 2003;14: 821-835.

28. de Queiroz AAA, Franca EJ, Abraham GA, San Roman J. Drug complexation and physicochemical properties of vinylpyrrolidone- $N, N^{\prime}$-dimethylacrylamide copolymers. J Appl Polym Sci 2004;93:1337-1347. 
29. Gallardo A, Fernandez F, Bermejo P, Rebuelta M, Cifuentes A, Diez-Masa JC, San Roman J. Controlled release of cyclosporine from VP_HEMA copolymer systems of adjustable resorption monitorized by MEKC. Biomaterials 2000;21:915-921.

30. de Queiroz AAA, Gallardo A, San Roman J. Vinylpyrrolidone- $N, N^{\prime}$-dimethylacrylamide water-soluble copolymers: Synthesis, physical-chemical properties and protein interactions. Biomaterials 2000;21:1631-1643.

31. Abraham GA, de Queiroz AAA, San Roman JS. Hydrophilic hybrid IPNs of segmented polyurethanes and copolymers of vinylpyrrolidone for applications in medicine. Biomaterials 2001;22:1971-1985.

32. Vazquez B, Elvira C, Levenfeld B, Pascual B, Goni I, Gurruchaga M, Ginebra MP, Gil FX, Planell JA, Liso PA, Rebuelta M, San Roman J. Application of tertiary amines with reduced toxicity to the curing process of acrylic bone cements. J Biomed Mater Res 1997;34:129-136.

33. Artola A, Gurruchaga M, Vazquez B, San Roman J, Goni I. Elimination of barium sulphate from acrylic bone cements. Use of two iodine-containing monomers. Biomaterials 2003; 24:4071-4080.

34. Harper EJ, Behiri JC, Bonfield W. Flexural and fatigue properties of a bone cement based upon polyethylmethacrylate and hydroxyapatite. J Mater Sci: Mater Med 1995;6:799-803.

35. Hutcheon GA, Messioub AC, Wyreb RM, Davies MC, Downesb S. Water absorption and surface properties of novel poly(ethylmethacrylate) polymer systems for use in bone and cartilage repair. Biomaterials 2001;22:667-676.

36. van Hooy-Corstjens CSJ, Aldenhoffa YBJ, Knetsch MLW, Govaert LE, Arin E, Erli H Koole LH. Radiopaque polymeric spinal cages: A prototype study. J Mater Chem 2004;14:30083013.

37. Gao TJ, Kousinioris NA, Wozney JM, Winn S, Uludag H. Synthetic thermoreversible polymers are compatible with osteoinductive activity of recombinant human bone morphogenetic protein 2. Tissue Eng 2002;8:429-440.

38. Vallet-Regi M, Gordo M, Ragel CV, Cabanas MV, San Roman J. Synthesis of ceramic-polymer-drug biocomposites at room temperature. Solid State Ionics 1997;101:887-892.

39. Kokubo T, Kushitani H, Sakka S, Kitsugi T, TY. Solutions able to reproduce in vivo surface structure changes in bioactive glass-ceramic A-W. J Biomed Mater Res 1990;24:721-734.

40. Peniche C, Zaldivar D, Bulay A, Sanroman J. Influence of chain microstructure on thermodegradative behavior of furfuryl methacrylate- $N$-vinylpyrrolidone random copolymers by thermogravimetry. J Appl Polym Sci 1993;50:2121-2127.

41. Peniche C, Zaldivar D, Bulay A, San Roman J. Influence of chain microstructure on thermodegradative behavior of furfuryl methacrylate- $N$-vinylpyrrolidone random copolymers by thermogravimetry. J Appl Polym Sci 1993;50:2121-2127.

42. Garrido L, Ibarra LM, Marco C. Ciencia y tecnologia de materiales poliméricos. Madrid, Spain: Instituto de Ciencia y Tecnología de Polímeros; 2004. p 158.

43. Moloney AC, Kausch HH, Stieger HR. The fracture of particulate-filled epoxy resins. J Mater Sci 1984;19:1125.
44. Vallo CI, Montemartini PE, Fanovich MA, Lopez JMP, Cuadrado TR. Polymethylmethacrylate-based bone cement modified with hydroxyapatite. J Biomed Mater Res (Appl Biomater) 1999;48:150-158.

45. Juhasz JA, Best SM, Brooks R, Kawashita M, Miyata N, Kokubo T, Nakamura T, Bonfield W. Mechanical properties of glass-ceramic A-W-polyethylene composites: Effect of filler content and particle size. Biomaterials 2004;25:949-955.

46. Vallo CI, Montemartini PE, Fanovich MA, Lopez JMP, Cuadrado TR. Polymethylmethacrylate-based bone cement modified with hydroxyapatite. J Biomed Mater Res 1999;48:150-158.

47. Tamura J, Kawanabe K, Kobayashi M, Nakamura T, Kokubo T, Yoshihara S, Shibuya T. Mechanical and biological properties of two types of bioactive bone cements containing MhgO-CaO- $-\mathrm{SiO}_{2}-\mathrm{P}_{2} \mathrm{O}_{5}-\mathrm{CaF}_{2}$ glass and glass ceramic powder. J Biomed Mater Res 1996;30:85-94.

48. Vuola J, Taurio R, Goransson H, Asko-Seljavaara S. Compressive strength of calcium carbonate and hydroxyapatite implants after bone-marrow-induced osteogenesis. Biomaterials 1998;19: 223-227.

49. Fernandez E, Gil FJ, Best SM, Ginebra MP, Driessens FCM, J.A.P. Improvement of the mechanical properties of new calcium phosphate bone cements in the $\mathrm{CaHPO}_{4}-a-\mathrm{Ca}_{3}\left(\mathrm{PO}_{4}\right)_{2}$ system: Compressive strength and microstructural development. J Biomed Mater Res 1998;41:560-567.

50. Yilmaz C, Korkmaz T. The reinforcement effect of nano and microfillers on fracture toughness of two provisional resin materials. Mater Des 2007;28:2063-2070.

51. Bogatyrev VM, Borisenko NV, Pokrovskii VA. Thermal degradation of polyvinylpyrrolidone on the surface of pyrogenic silica. Russ J Appl Chem 2001;74:839-844.

52. Grassie N, MacCallum JR. Thermal and photochemical degradation of poly( $n$-butyl methacrylate). J Polym Sci A: Polym Chem 1964;2:983-1000.

53. Smith SD, Long TE, McGrath JE. Thermogravimetric analysis of poly(methylmethacrylate-g-dimethyl siloxane) graft copolymers. J Polym Sci Part A: Polym Chem 1994;32:17471753.

54. Ragel CV, Vallet-Regi M, Rodriguez-Lorenzo LM. Preparation and in vitro bioactivity of hydroxyapatite/solgel glass biphasic material. Biomaterials 2002;23:1865-1872.

55. Mosmann T. Rapid colorimetric assay for cellular growth and survival: Application to proliferation and cytotoxic assays. J Immunol Methods. 1983;65:55-63.

56. Nakayama GR, Caton MC, Nova MP, Parandoosh Z. Assessment of the Alamar Blue assay for cellular growth and viability in vitro. J Immunol Methods 1997;204:205-208.

57. Wise DL, DJ Trantolo, DE Altobelli, MJ Yaszemski, JD Gresser, ER Schwartz, editors. Encyclopaedic Handbook of Biomaterials and Bioengineering, Part A: Materials. New York: Marcel Dekker; 1998;269-304.

58. Rea SM, Brooks RA, Best SM, Kokubo T, Bonfield W. Proliferation and differentiation of osteoblast-like cells on apatite-wollastonite/polyethylene composites. Biomaterials 2004;25:45034512. 